\title{
Development of a Selection Method of Favorable Juvenile Fish by Egg Weight in Masu Salmon (Oncorhynchus masou)
}

\author{
Yoshinari Uematsu ${ }^{1}$, Arimune Munakata ${ }^{2}$, and Hiroyuki Matsuda ${ }^{1}$ \\ ${ }^{1}$ Graduate School of Environment and Information Science, Yokohama National University, Yokohama, Kanagawa \\ 240-8501, Japan \\ ${ }^{2}$ Department of Biology, Miyagi University of Education, Sendai, Miyagi 980-0845, Japan
}

Keywords: egg weight, growth rate, masu salmon, Oncorhynchus masou, parr mark

Masu salmon (Oncorhynchus masou) is an important target for coastal fisheries in Japan (Hasegawa et al. 2021). However, the stock abundance of this salmon has been decreasing since the 1980's (Miyakoshi 2014). As a countermeasure, attempts have been made to increase the stock abundance by discharging juveniles (HRO 2013), but the effectiveness is low. One solution to this problem is to improve the quality of discharging juveniles by a selection method without genetic or hormonal treatments. Previous studies in chinook salmon (O. tshawytscha) have revealed that differences in egg weight resulted in different properties, such as growth rate and migration timing (Cogliati et al. 2018). Hence, selection by egg weight may contribute to improving quality of discharging juveniles in other species.

In this study, we selected eggs obtained from single and multiple female masu salmon by wet weight. In experiment 1, we divided eggs into larger $(>0.089 \mathrm{~g})$ and smaller $(<0.079 \mathrm{~g})$ groups in December 2018. In experiment 2 , we divided eggs into larger $(>0.084 \mathrm{~g})$ and smaller $(<0.079 \mathrm{~g})$ groups in December 2019. These eggs were reared in separate tanks of the same environment (Table 1). We selected 5 (exp. 1: Feb. to Sep. 2018), 10 (exp. 1: Oct. 2018 to Feb. 2019, exp. 2: Feb. to Sep. 2019), or 56 (exp. 2: Oct. 2019) juveniles from both groups, measured body weight (BW), and took photographs of left or both sides. Moreover, we measured standard length (SL), body surface and parr mark areas from the photographs by using "Image J" (Rasband 1997-2012), and calculated condition factor $\left(\mathrm{CF}: \mathrm{BW} / \mathrm{SL}^{3} \times 100\right)$ and parr mark area index (PAI: total parr mark area/body surface area $\times 100$ ). Significant differences between the two groups were verified by the student's $t$-test, and the significance level was less than $5 \%(p<0.05)$.

Table 1. Rearing environment of masu salmon juveniles from multiple females (exp. 1) and a single female (exp. 2)

\begin{tabular}{lcc}
\hline & Exp. 1 & Exp. 2 \\
\hline $\begin{array}{l}\text { Period } \\
\text { Fish number }\end{array} \quad$ Feb. 2018 to Feb. 2019 & Feb. to Oct. 2019 \\
$\quad$ (beginning $\rightarrow$ final) & Larger egg group $(80 \rightarrow 64)$ & Larger egg group (36 $\rightarrow$ 28) \\
Water temp. $\left({ }^{\circ} \mathrm{C}\right)$ & Smaller egg group $(80 \rightarrow 71)$ & Smaller egg group (36 $\rightarrow$ 28) \\
Feeding rate (per BW) & 18 (Jul.) to 10 (Dec.) & 18 (Jul.) to 12 (Oct.) \\
\hline
\end{tabular}

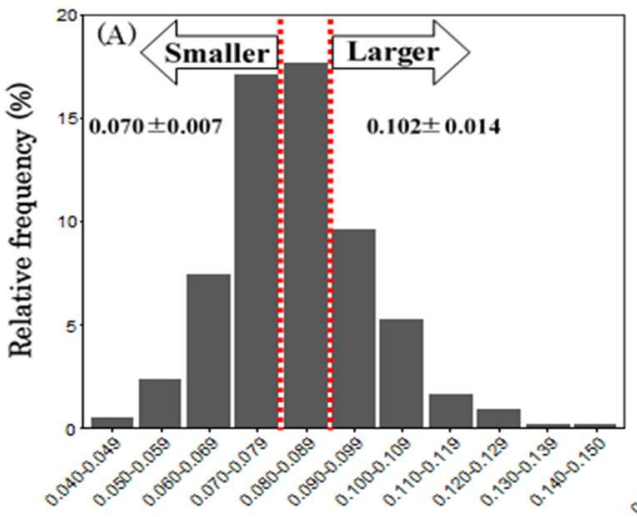

Egg weight (g)

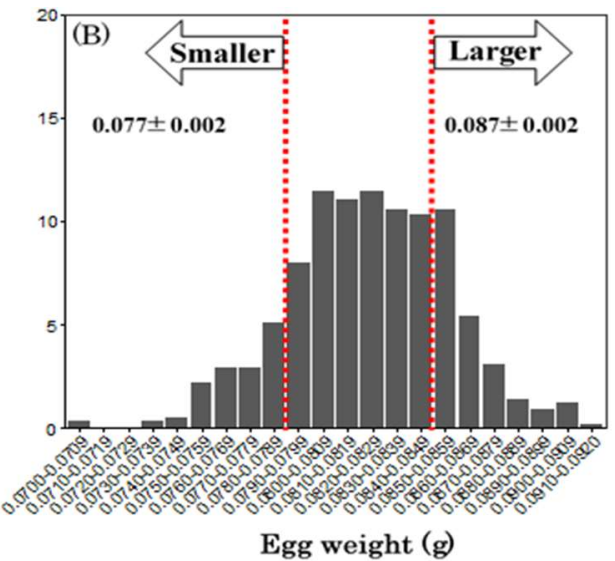

Egg weight $(\mathrm{g})$
Fig. 1. Egg weight distribution and selection standard in exp. 1 (A) and exp. 2 (B). The dashed lines show selection standard of the larger and the smaller egg groups, and the numbers in figures are average weight (mean $\pm \mathrm{SD}$ ). 
Mean egg weight $\pm \mathrm{SD}$ were $0.102 \pm 0.014 \mathrm{~g}$ and $0.070 \pm 0.007 \mathrm{~g}$ (exp. 1), and $0.087 \pm 0.002 \mathrm{~g}$ and $0.077 \pm$ $0.002 \mathrm{~g}$ (exp. 2) in the larger and the smaller egg groups, respectively (Fig. 1). In both experiments, the larger egg groups tended to show higher SL and BW values than the smaller egg groups in the early period (exp. 1: Feb. to Apr. 2018, exp. 2: Feb. to Mar. 2019). On the other hand, the smaller egg groups tended to show higher SL and BW values in a later period (exp. 1: Oct. 2018 to Feb. 2019, exp. 2: Aug. to Oct. 2019). There was no difference in CF values between the larger and smaller egg groups in both experiments. In PAI, the larger egg group tended to show higher values than the smaller egg group during the early (exp. 1: Feb. to May 2018, exp. 2: Feb. to Mar. 2019) and later period (exp. 1: Oct. 2018 to Feb. 2019, exp. 2: Apr. to Oct. 2019) (Figs. 2 and 3).
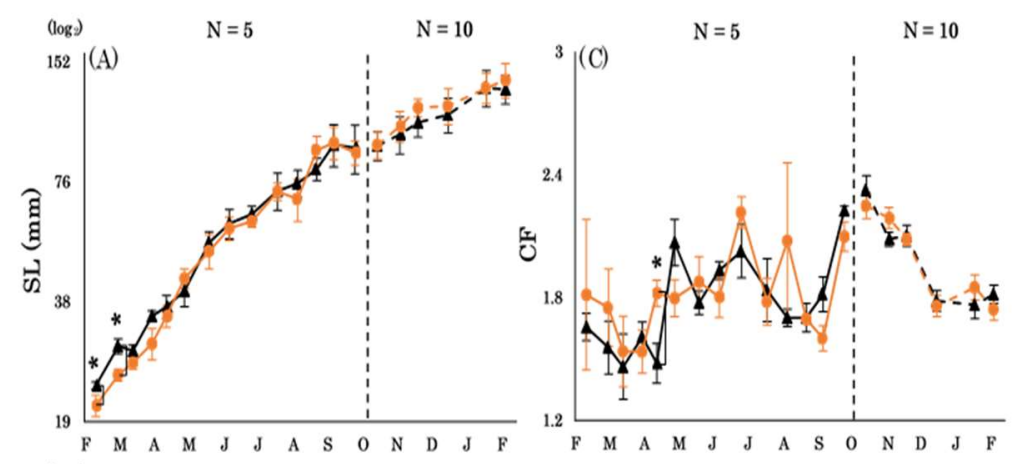

Fig. 2. Mean values (mean $\pm \mathrm{SE}$ ) of (A) standard body length (SL), (B) body weight (BW), (C) condition factor (CF), and (D) parr mark area index (PAI) of masu salmon in exp. 1. $\boldsymbol{\Delta}$ and $\bullet$ represent the larger and the smaller egg groups, respectively. The solid and broken lines are the result of five and ten individuals. The vertical lines in the figure are the boundary between five and ten individuals sampling. * Indicates significant difference at $p<0.05$.
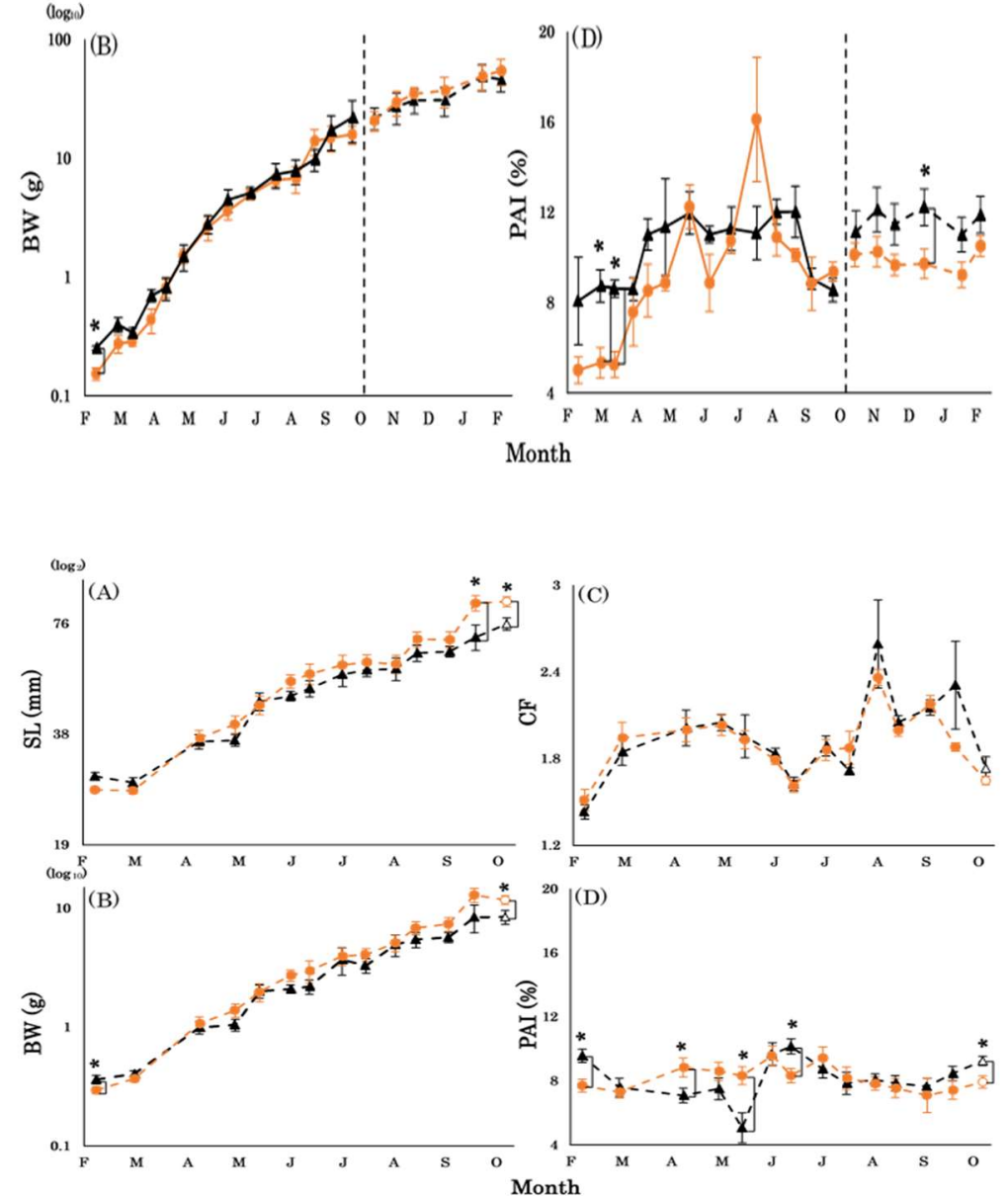

Fig. 3. Mean value (mean $\pm \mathrm{SE}$ ) of $(\mathrm{A})$ standard body length (SL), (B) body weight (BW), (C) condition factor (CF), and (D) parr mark area index (PAI) of masu salmon in exp. 2. $\boldsymbol{\Delta}$ and $\bullet$ represent the larger and the smaller egg groups, respectively. The 10 individuals were chosen randomly from both groups in all samplings except for the last sampling. The last sampling used all individuals of both groups $(n=56)$.

* Indicates significant difference at $p<0.05$.

As a result, the larger egg group tended to show higher SL and BW values in the early period, and the smaller egg group tended to show higher SL and BW values in the later period. The phenomenon observed in several salmonids suggested that individuals from large eggs showed larger body size than individuals from small eggs in the early life stage, and the body size difference disappeared with growth approximately 100 to 150 days after 
hatching (Ohkuma 2005; Bromage et al. 1992). This phenomenon is thought to be caused by different metabolic rates between groups. In previous studies, the southern population of masu salmon had a smaller egg size than the northern population in natural rivers (Morita et al. 2009). Seppänen et al. (2009a, b) also reported that the southern population of Atlantic salmon (Salmo salar) showed a higher metabolic rate than individuals of the northern population under common rearing conditions. Yamamoto et al. (1998) revealed a positive relationship between metabolic rate and growth in masu salmon. Based on this information, it seems that the individuals from the smaller eggs may have higher metabolic rates than the individuals from larger eggs. Thus, it is probable that the individuals from smaller eggs may show a higher growth rate than the individuals from larger eggs after discharging.

In PAI, the larger egg group tended to show higher values than the smaller egg groups throughout the experiment period (Figs. 2 and 3). The meaning and role of parr marks in salmonids are still unclear, except that it acts as a protective color (Donnelly 1985). It was reported that in river rainbow (O. mykiss) and cutthroat (O. clarkii bouvieri) trout resident juveniles have more parr marks than migrant juveniles (Northcote and Hartman 1988).

Therefore, the parr mark characteristics may be related to their migration characteristics, and individuals with high PAI (parr mark number $\times$ area) possibly have characteristics that allow them to remain in the river at a higher rate.

Based on these results, egg weight selection may choose juveniles that are suitable for the purpose of various discharges, such as the discharging for increasing the stock of the migrant and the resident types.

\section{REFERENCES}

Bromage, N., J. Jones, C. Randall, M. Thrush, B. Davies, J. Springate, J. Duston, and G. Barker. 1992. Broodstock management, fecundity, egg quality and the timing of egg production in the rainbow trout (Oncorhynchus mykiss). Aquaculture 100: 141-166.

Cogliati, M.K., J.R. Unrein, H.A. Stewart, C.B. Schreck, and D.L.G. Noakes. 2018. Egg size and emergence timing affect morphology and behavior in juvenile Chinook Salmon, Oncorhynchus tshawytscha. Ecol. Evol. 8(1): 778-789.

Donnelly, A.W. 1985. The adaptive significance of stream colouration: parr mark patterns and crypsis in coho salmon (Oncorhynchus kisutch). M.Sc. thesis. Simon Fraser University, Burnaby. 1-160.

Hasegawa, K., G. Sahashi, and S. Fukui. 2021. Masu Salmon, Oncorhynchus masou masou. Bull. Fish. Agency Jap. Jap. Fish. Res. Educ. Agency. 1-9. (Available at http://kokushi.fra.go.jp/R02/R02_63_CHE.pdf.) (In Japanese)

Hokkaido Research Organization (HRO). 2013. Masu salmon artificial seedling production. Hokkaido research organization fisheries research development marine net Hokkaido. (Available at https://www.hro.or.jp/list/fisheries/marine/o7ulkr000000d8y4.html) (In Japanese)

Miyakoshi, Y. 2014. Improvement of enhancement and conservation techniques for salmon stocks. Nippon Suisan Gakkaishi. 80(5): 674-676. (Available at https://www.jstage.jst.go.jp/article/suisan/80/5/80_WA2078/_pdf/char/ja.) (In Japanese)

Morita, K., T. Tamate, Y. Sugimoto, Y. Tago, T. Watanabe, H. Konaka, M. Sato, Y. Miyauchi, K. Ookuma, and T. Nagasawa. 2009. Latitudinal variation in egg size and number in anadromous masu salmon Oncorhynchus masou. J. Fish Biol. 74: 699-705.

Northcote, G.T., and G.F. Hartman. 1988. The biology and significance of stream trout populations (Salmo spp.) living above and below waterfalls. Pol. Arch. Hydrobiol. 35: 409-442.

Ohkuma, K. 2005. Egg size and early growth of masu salmon. Salmon and trout resource management center technical information. 171:15-19. (Available at https://dl.ndl.go.jp/view/download/digidepo_3505418 _po_tech_repo171_p15-19.pdf?content $\mathrm{No}_{0}=1 \&$ alternative $\mathrm{No}=$.) (In Japanese)

Rasband, W.S. Image J. U.S. National Institutes of Health, Bethesda, Maryland, USA, 1997-2012. (Available at http://rsb.info.nih.gov/ij/)

Seppänen, E., J. Piironen, and H. Huuskonen. 2009a. Standard metabolic rate, growth rate and smolting of the juveniles in three Atlantic salmon stocks. Boreal Environment Research 14(3): 369-381. (Available at https://helda.helsinki.fi/bitstream/handle/10138/233457/ber14-3-369.pdf?sequence=1.)

Seppänen, E., K. Tiira, H. Huuskonen, and J. Piironen. 2009b. Metabolic rate, growth and aggressiveness in three Atlantic salmon Salmo salar populations. J. Fish Biol. 74: 562-575.

Yamamoto, T., H. Ueda, and S. Higashi. 1998. Correlation among dominance status, metabolic rate and otolith size in masu salmon. J. Fish Biol. 52: 281-290. 